ISSN 0975-3311

Ushus JBMgt, 9, 2 (2010) 19-30

ISSN 0975-3311 | https://doi.org/10.12725/ujbm.17.2

\title{
TAKE CARE OF THE 3 P'S THAT WILL TAKE CARE OF YOUR BUSINESS
}

\section{J. J. Soundararaj*}

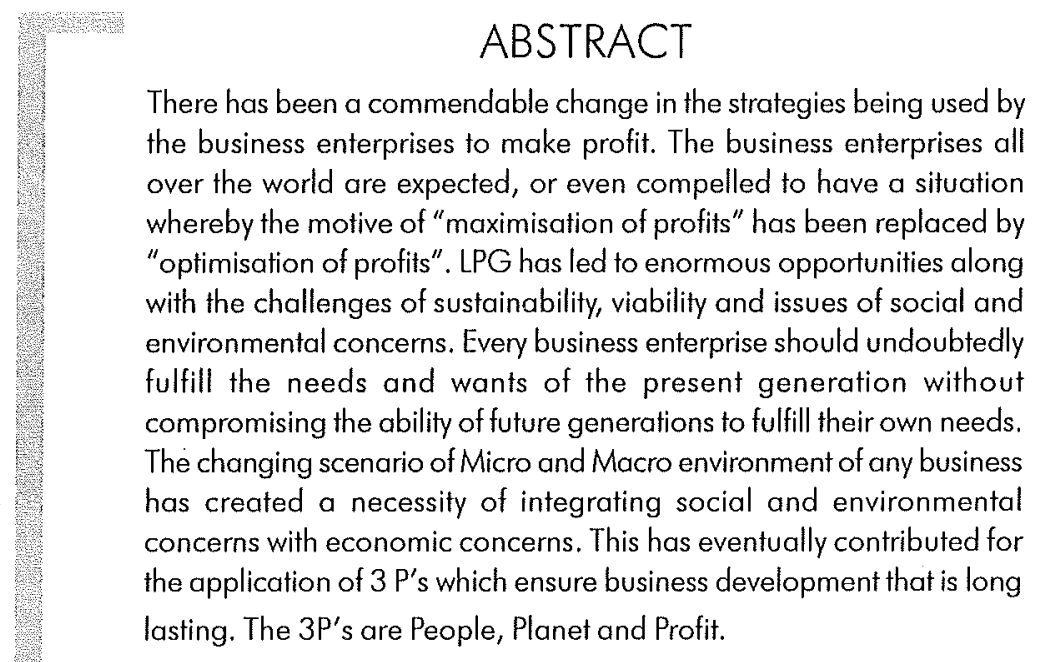

* Dept. of Commerce, Loyola College,Chennai-600 034, E-mail: jamesloyola@gmail.com 


\section{Introduction}

In the globalised village, any business enterprise should certainly believe that 'Profit is not a dirty word'. Perhaps, 'Profit' is the fundamental reason behind the existence of every business organisation. Traditionally, Business enterprises were working mainly towards maximisation of profits. But today, the Business enterprises are expected, or even compelled to have a situation whereby the motive of "maximisation of profits" has been replaced by "optimisation of profits". Furthermore, there has been a commendable change in the strategies being used by the business enterprises to make profit. On one hand, LPG (Liberalisation, Privatisation and globalisation) has provided enormous opportunity for business enterprises to expand their market share and production bases, but on the other hand, LPG has led to the challenges of sustainability, viability and issues of social and environmental concerns. This new and changing global business environment has made all business enterprises to voluntarily integrate social and environmental concerns into their business policies and operations. Every business enterprise that desires to become sustainable should undoubtedly fulfill the needs and wants of the present generation without compromising the ability of future generations to fulfill their own needs. The ways and means to be followed to integrate social, environmental and economic concerns together in a balanced manner have been detailed in this essay.

\section{The 3 P's and their Relevance for Sustainability}

It is imperative for any business to earn profit which guarantees its survival and growth. In the past, invariably all the business enterprises were involving themselves to make their profit by catering for the needs and wants of their direct target consumers better than that of the competitors. Many organizations did not bother about serving their target consumers even at the cost of the other general public and also the ecological environment. But today, the business enterprises are restricted by the forces from legal environment as well as various public/people forums/associations to serve the target consumers without compromising the interest of general public and the ecological environment. This new practice suggested to be followed is similar to 'Societal marketing Concept'. For example, Britannia Industries Limited (BIL) is promoting a slogan of "Eat healthy, think better". The slogan of Britannia (BIL) is purely societal marketing oriented which is a general message to everyone in the society where its consumers form a part 
only. If the Organisations of this modern business world desire to fulfill the interest of their owners/ shareholders satisfactorily and consistently, they have to aim for growing and sustained amount of profitability in the long term. Such profitability could be achieved only when the organizations integrate social and environmental concerns with economic concerns. This has eventually contributed for the application of $3 P^{\prime}$ 's which ensure sustainable business development. The 3P's are People, Planet and Profit. The $3 \mathrm{P}^{\prime} \mathrm{s}$ are very purposely presented in their order of priority. An organisation which takes care of people, planet and Profit in this order of priority obviously caters for the needs of the society, environment and investors respectively.

\section{People}

The very first ' $P$ ' that has to be taken care by the business enterprises is People. People here refer to the people in and around the organisation. The people inside the organisation are the employees working for the organisation and the people at outside refer to the general public that includes target consumers also. It is a well known fact that more satisfied internal Customers (employees) make more delightful External customers. Some of the ways through which Business enterprises can take care of the interest of employees and make them happy are suggested and discussed here.

Develop a good culture- A culture that encourages interaction, feedback and exchange of ideas should be created. 'Staples' touts what it calls its "Me 3rd Culture." Employees are told that to succeed at Staples they must think Staples first, their team second, and themselves third. The knowledge, intelligence and skills of the employees are as valuable to the business as any other asset. Therefore, efforts should be made to make use of them to the maximum. The culture developed should eventually stand for 'Respect for every individual'.

Take up responsibility - In especially organisations that are headed by the people belong to low context culture, the top management does not take up the responsibility, instead it passes the blame for the mistakes on the heads of its' subordinates. The top management should always come forward to take up complete responsibility for any major mistakes taken place in an organisation. 
Promote collaboration, not competition- It is a myth that competition will motivate creativity among the employees. In fact, it may have opposite effect. When the creative process is made competitive by using incentives like money, fear or deadlines, it puts undue pressure on the employees. On the other hand, a culture that stresses on team work will motivate employees to share ideas freely and influence organisational culture positively.

Inculcate the sense of belongingness- It is important for an organistaion to inculcate the sense of belongingness in every employee. Only when an employee feels that he/ she is an asset and a part of the organisation, he/ she relates him/ herself positively to the organisation.

Investment on healthcare of employees- This investment will certainly result in worthy benefits both to the company and the community in general. Healthcare efforts will lead to reduced absenteeism, lower attrition and increased productivity which can have a positive impact on the companies' bottom line and also contribute for building a healthier society.

Provision for open and honest communication- The open and honest two way communication facilitates better understanding of the communication and also gives an opportunity for both the parties involved in the communication to interact with one another more effectively and confirm the reach of the communication as intended by the party communicated. The employees could be encouraged to give their suggestions on important issues related to the interest and future of the organisation. Workers participation in planning and decision making gives them a sense of ownership over the plans and decisions and eventually activates them to put in their best in the execution process of such plans and decisions. Above all, what is expected of each employee by the organisation should be well communicated to the best of employee's understanding.

Provide positive leadership- It is imperative to provide positive leadership in all sections and divisions of an organisation. Only positive heads can inspire the subordinates and guide them towards right direction.

Investment in training and development- Whether it is a period of recession or boom, Human Resources are assumed to be the most valuable asset of an organisation. The Business enterprises that accept this fact and continue investing in their Human Resources and on their development will reap the benefits of employee involvement and commitment. 
Apply practical measures for appraising and improving performance- The procedure for evaluation of performance has to be quite transparent. Appraisals are to be shared and discussed with people concerned. Managers could be appraised with reference to the core values and the ratings are to be linked to compensation packages they receive. Employees are to be trained to undertake the performance appraisal seriously. It is imperative that every employee should be given with constructive criticism about their performance by the officials in charge of appraisals so that the employees could be asked to come out with their own plans to improve upon their performance. The officials doing the appraisals should have gained credibility from the view point of the employees who undergo such appraisals. Self-appraisal could also be activated in addition to the appraisals done by the superiors/ officials.

Strategic recruitment and selection- Strategic recruitment and selection is nothing but the recruitment and selection of employees at any level of management in an organisation keeping in mind the organisation's mission and strategic business objectives. At present globally, companies are striving to gain competitive advantage by appointing and retaining Quality workforce. When the employees are selected on line with the requirements of the strategic business objectives, the crucial problem of high attrition rate could be eliminated considerably. It would be worth saying that strategic recruitment and selection ensures keeping the right people in right place. This activity helps employees to find colleagues who are capable and competent enough to form productive teams.

Under-promise \& over-Deliver- Keeping the promise is inevitable for the employers to build a team of satisfied employees. When an employer under-promises \& over-delivers, he/ she makes the employees delighted by providing them value that is more than their expectation. Only delighted employees tend to become loyal to the organisation and who could also be retained by the organisation. If an employer does the opposite - overpromising and under-delivering - he/she will quickly gain a reputation of incompetence. The concept, under-promise does not mean that it should be below than that of the industry as because the promise which is lower than that of the industry would make the employers handicapped in attracting the appropriate type of human resource from the labour market.

Job Security- Job security is imperative for making the employees to show greater involvement and commitment to the job and also be loyal to the 
organisation. It is believed that employees whose jobs are secured are motivated and more productive, whereas the other group of employees whose jobs are unsecured always put into a kind mental agony and consistently worrying about retaining the job. Job security should be guaranteed to all the employees who have proved themselves in their respective jobs.

Growth opportunity and rewards- The whole array of HR functions (including remuneration, career development, succession planning, recruitment and training etc) must all be coordinated at a strategic level to bind good people to the organisation. Moreover, it is ethically correct to say that the employees have every right to grow with their organisation. When the organisation grows in terms of size, value, profits etc, if the employees are left behind the benefits arisen out of such changes, it is said that the employees are not growing with the organisation. Such a situation never makes the employees happy.

Discrimination and harassment- The organisation should be committed to providing a workplace free from discrimination and harassment based on race, color, religion, age, gender, national origin, disability or any other biases. It would be the endeavour of everyone in an organisation to see that the work place is free from such discrimination and harassment. This aspect gains more importance in organisations where employees of both the sex working together and also where people from different culture working together in a cross-cultural environment.

Organisational Structure- In order to encourage employee commitment, most of the organisations have a minimised hierarchical management process and they also empower employees with many key business decisions. In some of the organisations, Cross-functional teams have been constituted for better decision-making on key issues. At Kellogg's, biweekly and bimonthly cross-functional team meetings are held. A well established organisational structure would certainly make the employees happy and comfortable.

Other practices - There are other practices which would also facilitate an employer to make his/her employees happy. They are:- Facilities for child care; Financial planning senvices for employees who need them; Flexi timings; Work sharing; Part time employment; Subsidised food plans; Insurance plans; Counseling services for problems like managing work and the home; Rest rooms; Jobs with autonomy and flexibility; Realistic 
work loads; Birthday celebrations; Get-togethers and annual picnic; and Payment of salaries and wages on time.

There are many ways by which an organisation can take care of the interest of target consumers and general public who are the people at outside. Some of them have been discussed here.

Selling the right product at right selling price- It is in fact a moral responsibility of every business enterprise to offer the right product/ service at right selling price to the target consumers. Offering right product/ service to right people facilitates choosing the right consumers and tailors all marketing activities upon them. This activity helps the consumers to choose and buy only the products and services meant for them.

Making the products available at the places and time of convenience- Appropriate distribution/ availability of products is another important activity that influences a consumer's choice of brand preference. Moreover, when a preferred brand is made available at the places and time of convenience for consumers, there is no room for them to think of an alternative brand.

Upgrading the product- The product which was perceived to be the best yesterday is not treated to the same today if it is not upgraded in terms consumers expectations that are changing quickly. Therefore, it is necessary to upgrade the product whenever it is expected and needed.

More add on services at free of cost- In relation to the levels of product suggested by the marketers, there is a level called, augmented product. It should be built with as many consumer's preferred features as possible. They could be provided with the sale of product or service at free of cost.

Communication and education- Many a times, not all the consumers have clear idea about the product's features, usage and benefits etc. In this situation, the marketers should have the pleasure of communicating the required information to the consumers and educate them about their offering.

Building long lasting relationship with customers- The modern marketers should take efforts to build a relationship which is more than mere a business relationship with the customers. This relationship would certainly guarantee them always a size of revenue irrespective of changing conditions in the competitive environment. 
Sponsoring community activities- In the present day, many corporations widely involve and commit themselves towards community activities. They sponsor the education of the neighbourhood and donating money for the conduct of traditional festivals, religious activities and other local celebrations. Moreover, the corporations spend money to carry out periodic healthcare and free vaccination programmes for the people around them. During the times of disaster by natural calamities, the role of few corporations in helping the people around is really appreciated. For example, Indian companies like Tata Group, Birla Group and Maruti Udyog have earned very good name for themselves as socially responsible companies.

Provision of employment- It is the moral responsibility of every corporation to develop and impart skills to the human resource in the neighbourhood and eventually employs them to the extent possible. This activity is assumed to be very important in building societies of especially developing and under developed countries.

Ethics in business- The socially responsible companies which follow ethical practices command lot more respect and loyalty from the general public. In India, Tata Group, Birla Group and Infosys have been positioned well in the minds of the public because of their ethical practices.

Above all, tangible cost savings, enhanced customer loyalty or top talent retention and Corporate Social Responsibility (CSR) initiatives benefit the companies as much as they help the society. As far as India is concerned, the concept of Social Responsibility is not new to India; contributing to society without expecting anything in return is an intrinsic part of Indian tradition. But it cannot be denied that this activity needs to be strengthening more in countries such as India where about forty percent of the population is reeling under the vicious clutches of social maladies like poverty and illiteracy. This is not only because of the shortage of material resources but also because of social, political and economic structures. Social Responsibility implies rising corporate behaviour upto a level where it is in congruence with currently prevailing social norms, values and expectations of performance.

\section{Planet}

The second ' $P$ ' among the said $3 P$ 's refers to Planet. The social responsibility concept proposes that every management should evaluate all its activities 
or services in terms of social cost and benefits before deciding whether to proceed with an activity or service. Social costs would be given more value in the decision making process. Businesses have to think in terms of costs. There may be some business plans which might appear to be profitable during the short term, but taking its long term costs, they may result in social costs. For example, location of an industrial unit near the thickly populated area may have benefit in short term. But in long term such a decision may prove harmful to the society as its effluents and gas may create problems to the society as a whole in the form of health hazards etc. These problems in turn may result in additional social costs. The basic criterion is whether the social benefits outweigh the socials costs so that there is a net social benefit. There are few constructive ways by which every organisation could contribute for keeping the planet in such a way that would be of more beneficial to the present generation without exploiting the right of next generation on the planet. The few ways suggested to corporations to preserve the planet are discussed here.

Efficient utilisation of natural resources- It is a known fact that many of the natural resources are scarce in nature. Such resources are to be utilised by the corporations meticulously. If possible, alternative means of doing the same thing should be explored by the organisation's research and development process. Utilisation of natural resources should be kept as last resort for any manufacturing process.

Allocation of natural resources- The allocation of natural resources to different purposes and businesses should be done keeping the priorities of human kind in mind. In fact, the intervention of Government is encouraged in this activity.

Taking Global stock in to account- In the era of globalisation, efforts are required to be taken by the governments of different nations of the world to look at the stock position and allocation of natural resources with a global view.

Helping to create pollution free environment- It is understood that there arise different sort of pollution while converting the input into output in any manufacturing process. But, the impact of such pollution could either be avoided or reduced by means of some technologies and methods. For example, the molasses that come out of leather tanneries could be converted into fertilizers by further processing. Likewise, in other industries also, such 
remedial measures are required to be found out to help the society to keep up the planet in good condition.

Avoidance of using input that would spoil the planet- Many companies do not bother about what is in the materials they use in their products. In reality, every product, process and service has an environmental impact. As part of sustainability initiatives, companies should work in collaboration with their suppliers to design and manufacture products using environmentally friendly processes, raw materials and packaging. Producing energy efficient and less polluting products will be a big boon to the society. The business enterprises should always avoid using the material which would go against the interest of the planet. It might be chemicals, plastics, a method of production or any other content. Even if the usage of such things is more cost effective, they should be certainly avoided processing in order to protect the well being of the planet.

Compromise growth to protect the planet- Growth is inevitable for every business organisation. But, it is no bad if such a growth of a business is compromised when it has to be achieved at the cost of damaging the planet.

It would be apt saying that it is the responsibility of all individuals, forums, associations, organisations and Government to involve in activities that would protect the Planet which is the most beautiful gift one generation leaves to next generation. In the movement to protect the planet, the role of corporations in terms of funding related activities such as eco-friendly activities and also avoiding the activities of disinterest in relation to planet is very important.

\section{Profit}

The third ' $P$ ' among the said $3 P$ 's refers to Profit. Perhaps, making profit is imperative for the existence and continuity of any business enterprise. When there is no profit, there is no existence of business. Profit is the final outcome expected after all the activities carried out by a business enterprise. Taking care of the people and planet also eventually results in profit for a business. On the whole, the performance of an organisation is eventually measured in terms of profit it makes at the end the period. While serving the society and protecting the planet, the interest of the owners/ shareholders who have invested their money in the organisations should also be taken 
care. Achieving desired return on capital employed is the one which determines the life of the business in the long term. Desired return on capital employed means a fair return, to be achieved not by exploiting the interest of the people. Another important point to be worth noting here is that the cost of providing the social benefits should not be charged upon the heads of consumers. Instead, it should be borne by the owners/ shareholders of the business. It is further suggested that a portion of the revenue should be used to meet out the social costs. This is the very reason which has led the business enterprises to find a change from "Maximisation of profits" to "Optimisation of profits". Since there have been many studies or researches that have suggested the ways to take care of the PROFIT, this article has not highlighted them in detail.

\section{Conclusion}

The capitalism that dominates today's global economy has, on the one hand, reduced the ability of governments to regulate business activities and, on the other hand, increased corporate power and influence. Corporations are important and powerful players in today's world. But business activities often leave irreversible social, economic and environmental impacts on surrounding communities and the world at large. Development that is sustainable and not damaging the natural resources is very much possible. The economic, social and environmental aspects must be integrated in a systematic and balanced manner. Protection of environment should not be assumed to be a sectored interest but to be an integrated part in all economic and social development. The businessmen should be aware of the consequences of their activities on the society. They should concentrate on actions that safeguard and enhance social interests. The fundamental concept is based on the philosophy of trusteeship i.e, the society has entrusted to business and industry, a greater amount of its scarce resources and, therefore, business and industry should manage these resources as a wise trustee of the society. Therefore, it could be concluded saying that it is in the interest of every stakeholder associated with a business that all the organisations should try to find a strategic fit between social, environmental and economic concerns which will eventually take care of the interests of the business and make it sustainable. 


\section{References}

- Bindu Sridhar., 'Leadership always dictates employee engagement". The Hindu-7"h January 2009.

- Bindu Sridhar., "A culture that stresses on team spirit fosters creativity"- The Hindu$24^{\text {th }}$ December 2008

- "Corporate Social responsibility, putting principles into practice" - a Tata Steel publication

- Fernando, A.C., "Corporate Governance- The time for a Metamorphosis". The Hindu$9^{\text {th July }} 1997$

- Janakidass, D.V.S., and Soundararaj, J,J., April 2007 "Internal Marketing-an 'Upskilling process' for the Internal Customers", Marketing Mastermind., ICFAl University Press,

- Jim Blythe., Essentials of Marketing, $2^{\text {nd }}$ edition England, Pearson Education Limited, 2001).

- Purnima Srikrishna, N., "CSR makes perfect business sense"- The Hindu-7" January 2009

- Soundararaj.J.J., June 2009, "Inevitability of $3 \mathrm{P}^{\prime}$ s for Sustainable Development", Readers Shelf., Volume.5, Issue No.9, Pages-19 \& 20, J.V.Publishing House,

\section{Websites}

- http://en.wikipedia,org/wiki/corporatesocialresponsibility

- hHp://www.britannia.co.in/companyoverview_overview.htm

- http://www.businesstoolchest.com/articles/data/20051117201010.shtml

- http://www.thehindubusinessline.com/2005/07/18/stories/ 2005071800420900.htm

- http://articles.manupatra.com/ 